\title{
Investigation of the relationship between age and the angle of aortic insertion on the left ventricle using 3D MRI
}

\author{
Raphael D Hazel ${ }^{1,2^{*}}$, Simcha Pollack ${ }^{2}$, Nathaniel Reichek ${ }^{2}$ \\ From 15th Annual SCMR Scientific Sessions \\ Orlando, FL, USA. 2-5 February 2012
}

\section{Summary}

There is a gradual increase in the insertion angle of the aorta on the left ventricle with increasing body mass index, however the increase of this angle with age in non-obese subjects is not well understood.

\section{Background}

The aortic insertion angle (IA) is generally believed to increase with age, but this relationship has not been verified. The objective of this study was to determine the relationship between the IA of the aorta and demographic variables in humans from 3D MRI.

\section{Methods}

Thirty four volunteers (17 males) with an average age of $53 \pm 17$ years were consented for this study after IRB approval. Images were acquired on a 1.5 Tesla Siemens Avanto (Siemens Medical Systems, Malvern, PA) MRI scanner with an 8 channel cardiac coil and 3D SSFP pulse sequence. Images were acquired in diastole by a delayed trigger. Sequence parameters were $\mathrm{TR} / \mathrm{TE}=$ $319.5 / 1.3 \mathrm{~ms}$, Flip Angle $=66^{\circ}, \mathrm{FOV}=250 \times 360 \mathrm{~mm}$, matrix $256 \times 180$, slice thickness $4-6 \mathrm{~mm}$. A 3D volume of 20-40 axial slices covering the LV and ascending aorta was acquired in a single breath-hold. In addition, in one subject, 3D volumes at each of 22 phases of the cardiac cycle were obtained. Images were interpolated to produce a $3 \mathrm{D}$ matrix with a spatial resolution of $1.40 \mathrm{~mm} 3$. The IA was defined as the angle between a line connecting the apex and the center of the mitral annulus, and the line through the center of the aortic valve and the center of the aortic lumen

${ }^{1}$ Singapore Biolmaging Consortium, BioMedical Sciences Institute, Singapore, Singapore

Full list of author information is available at the end of the article

beyond the sinotubular junction. IA measurements were made with in-house software (Matlab, the MathWorks, Natick, MA) and validated with phantom images. Each IA is the average of 5 independent measurements.

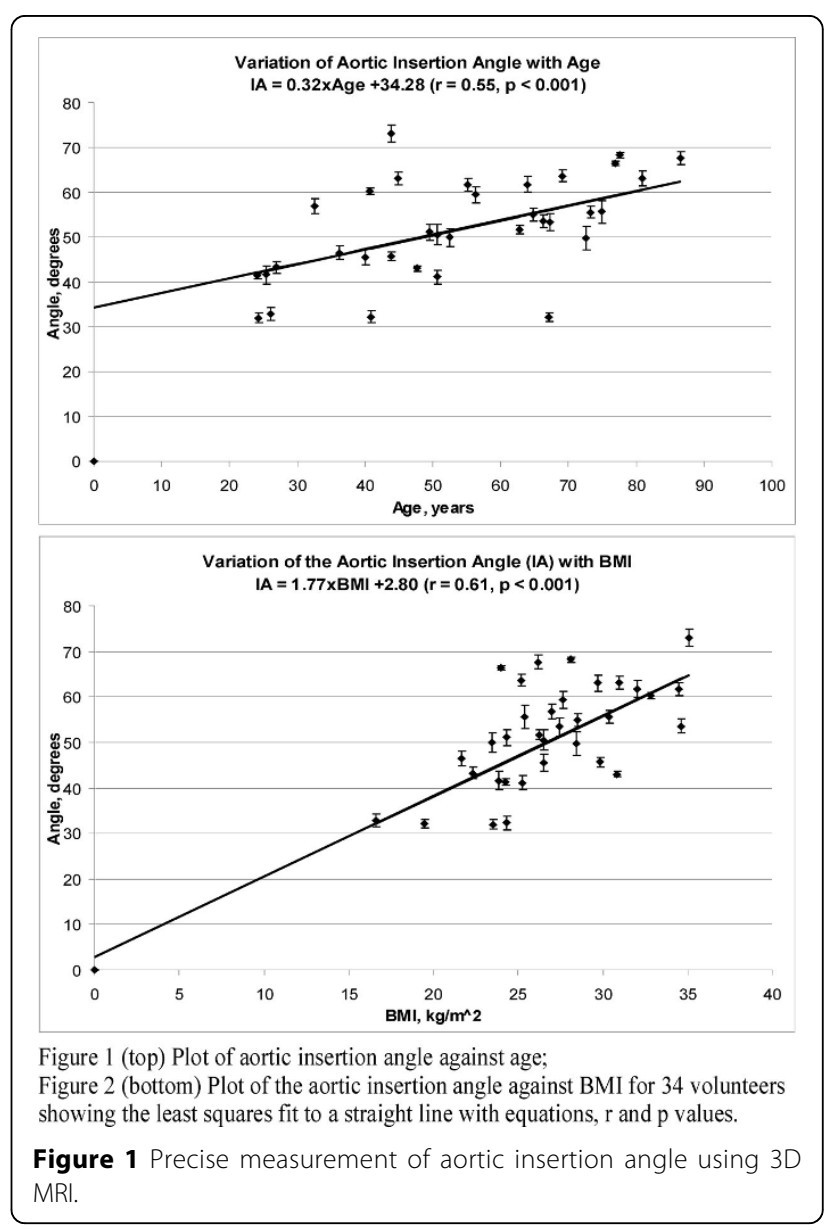

C Biomed Central

(0) 2012 Hazel et al; licensee BioMed Central Ltd. This is an open access article distributed under the terms of the Creative Commons Attribution License (http://creativecommons.org/licenses/by/2.0), which permits unrestricted use, distribution, and reproduction in any medium, provided the original work is properly cited. 


\section{Results}

There is a strong correlation overall between IA and BMI $(\mathrm{r}=0.61, \mathrm{p}<0.001)$. However, in non-obese subjects, IA appears to increase with age $(\mathrm{r}=0.55, \mathrm{p}<0.001)$. There is a weak correlation between IA and weight $(\mathrm{r}=0.45, \mathrm{p}$ $=0.008$ ), but no significant correlation between IA and height or gender or body surface area.

\section{Conclusions}

The insertion angle of the aorta on the left ventricle increases with body mass index.

\section{Funding}

St Francis Hospital, 100 Port Washington Blvd, Roslyn, New York.

\section{Author details}

${ }^{1}$ Singapore Biolmaging Consortium, BioMedical Sciences Institute, Singapore, Singapore. ${ }^{2}$ Research and Education Foundation, St Francis Hospital, Roslyn, NY, USA.

Published: 1 February 2012

doi:10.1186/1532-429X-14-S1-P77

Cite this article as: Hazel et al:: Investigation of the relationship between age and the angle of aortic insertion on the left ventricle using 3D MRI. Journal of Cardiovascular Magnetic Resonance 2012 14(Suppl 1):P77.

Submit your next manuscript to BioMed Central and take full advantage of:

- Convenient online submission

- Thorough peer review

- No space constraints or color figure charges

- Immediate publication on acceptance

- Inclusion in PubMed, CAS, Scopus and Google Scholar

- Research which is freely available for redistribution

Submit your manuscript at www.biomedcentral.com/submit 